\title{
Influencers y Derecho de la Competencia
}

Christian Vidal Beros ${ }^{(1)}$

Resumen: Se analiza el nacimiento del fenómeno de los influencers dentro de la publicidad ligada a redes sociales y tecnología y su necesaria regulación por parte del Derecho. Se presenta la importancia de delimitar y definir cuándo la promoción de un producto a través de estos influencers, es pagada o no y las consecuencias jurídicas para el libre mercado y los consumidores de ello.

Palabras claves: Influencers - Derecho - Publicidad - Competencia desleal - Regulación.

[Resúmenes en inglés y portugués en la página 106]

(1) Licenciado en Derecho, Abogado de la P. Universidad Católica de Chile. Máster en Derecho por la Universidad de Salamanca, España y Doctorando de la misma casa de estudios. Postgrado en Derecho Público Global de la Universidad de Castilla La Mancha. Profesor de la Facultad de Derecho de la Universidad Andrés Bello y de la Facultad de Economía y Negocios de la Universidad Finis Terrae, ambas de Santiago de Chile.

\section{Introducción}

El presente trabajo analiza el concepto de influencer y su nacimiento, tanto en el mundo digital de las redes sociales como en el de la publicidad, y cómo dio lugar a relaciones mercantiles o laborales necesariamente reguladas por el Derecho. Respecto a dicha regulación, se analiza la relación con el Derecho regulatorio, específicamente la competencia desleal y el derecho del consumo.

Podemos comenzar señalando que la publicidad contemporánea ha vivido una transformación considerable desde la llegada del nuevo siglo. Con el nacimiento de Internet en la década de los noventa del siglo XX y de las redes sociales, la forma de llegar a los consumidores y público en general, se volvió inmediata, instantánea y -ayudada por la inteligencia de negocios-, más efectiva.

Dentro del mundo de la publicidad, se ha analizado la relación existente con uno de los rubros que no solamente mayor presupuesto invierte en la misma, sino que además ha podido generar a través de la historia, un mayor número de novedades o tendencias al 
momento de dar a conocer un producto: La industria de la moda. En efecto, la relación de la moda no solamente con la publicidad, sino que también con el mundo del Derecho se ha comenzado a analizar con la llegada del siglo XXI, por medio de distintas corrientes de estudio, comenzando por universidades americanas, para luego expandir este nuevo objeto de estudio jurídico por Europa y América Latina ${ }^{1}$.

Ha sido el Derecho de la moda, el que tímidamente ha ido reconociendo nuevas realidades jurídicas relacionadas con los derechos fundamentales, el derecho de la propiedad intelectual, el derecho del trabajo, la regulación económica y la facultad normativa y/o sancionatoria del Estado, entre otros. Dentro de esas nuevas realidades jurídicas, la forma por medio de la cual las empresas y las marcas llegan al público, sin duda han variado, con mutaciones que han requerido un respaldo jurídico tan rápido como se han ido dando en la práctica.

Comenzaremos delimitando el concepto de "influencers", la naturaleza de su regulación jurídica, y cómo el derecho regulatorio se relaciona con esta actividad publicitaria.

\section{Desarrollo}

\section{a. Influencers. Concepto. Evolución. Nueva realidad publicitaria}

En relación a otras industrias, el mundo de la moda es un mercado donde la importancia de la imagen toma protagonismo. No solo la "imagen de marca", sino que también la imagen de los diversos protagonistas en el mercado del vestuario y sus accesorios: Diseñadores, modelos, como también nuevos formatos de canales de comunicación, como son las celebrities, los "embajadores de marca" y los "influencers".

Bajo esta nueva manera de estructurar la publicidad, surgió un producto típico de las redes sociales, los denominados influencers, definiéndolos como

Personas que tienen la capacidad de influir en el comportamiento de consumidores de manera mucho más incisiva que la publicidad tradicional, y de ahí que los fabricantes y las marcas se fijen en ellos para la promoción de sus productos y servicios (Diez, 2018) ${ }^{2}$.

Efectivamente, el nuevo rol de las redes sociales trasciende al contenido compartido. Redes donde una parte -conocida o no-, mostraba o compartía videos o fotografías, han evolucionado a la Web 2.0, donde el usuario es el centro del contenido, Los consumidores no solo son receptores de información; pueden generar y comunicar contenido propio, "democratizando" el uso y manejo de las redes sociales. Los influencers son atractivos vehículos para las marcas de moda en su carrera por llegar a los consumidores finales, dado el alto nivel de adherencia y número de sus seguidores, con los que comparten el mismo idioma digital. Así, los influencers pueden subir a sus redes sociales contenido propio o bien un contenido ya producido por la propia marca, siendo ellos meros intermediarios en la publicidad. En 
las próximas páginas analizaremos la naturaleza de los acuerdos de promoción, sus aristas regulatorias y los posibles conflictos de derechos.

\section{b. Influencers y regulación jurídica ${ }^{3}$}

La primera aproximación que podemos hacer al mundo de los influencers es a través del Derecho de la moda, disciplina que ha comenzado a analizar el conjunto de relaciones jurídicas al interior de dicha industria. Si bien los influencers traspasan las fronteras de la moda, llegando al deporte, la cocina u otras disciplinas, son aquellos que se dedican a promocionar indumentaria y tendencias, quienes han logrado posicionar a las marcas que representan, de mejor manera, y en forma más rentable.

La relación del influencer con la marca que promociona no está prevista por el Derecho. Nos encontramos muchas veces frente a contratos innominados y de características sui generis, completamente inéditos para la norma. Algunos considerarán que estamos en presencia de contratos de publicidad, otros asimilarán la función del influencer con la de un distribuidor, pero en ambos casos, el rol del personaje excede o no alcanza a satisfacer la naturaleza jurídica de dichos contratos.

Coincidimos con Carbajo Cascón (2015, p. 126) cuando indica que el rol del influencer cabría dentro de una de las partes del engranaje de la distribución, ya que ésta

(...) comprende diferentes actividades empresariales que tienen como objetivo último poner a disposición de los potenciales clientes todo tipo de productos y servicios, lo cual implica el acercamiento físico de los productos al destinatario, la prestación de los servicios complementarios a la comercialización, la promoción comercial para la generación de demanda o la asistencia preventa y postventa al cliente.

Si bien el rol de estos comunicadores cabría dentro del proceso de distribución, ciertamente es un aspecto puntual, alejado de la completitud de la distribución propiamente tal, como lo señala el autor español. En efecto, el rol del influencer es promocionar comercialmente un bien o servicio, pero exclusivamente enfocado en publicitar los beneficios del mismo. Existe una serie de procesos que escapan al rol del personaje y que forman parte de la distribución, como la concesión mercantil, el suministro, o los acuerdos marco en los que existe un compromiso total por parte del distribuidor asumiendo a su cuenta y riesgo las gestiones y los resultados del negocio; todo lo cual excede de las responsabilidades de un influencer al promocionar una determinada marca o producto.

Dependerá de la norma a aplicar, si estamos frente a influencers que solamente promocionan productos o servicios ajenos, ya sea en sus distintas redes sociales y además por ejemplo fuera de ellas. Asimismo, será relevante si nos encontramos frente a influencers que no sólo publicitan contenido ajeno, sino que pueden igualmente crear contenido propio, como por ejemplo los videos de los denominados youtubers.

Siguiendo a Díez, el análisis del tipo de relaciones jurídicas existentes entre el influencer y sus marcas-clientes, debe comenzar por distinguir tres aspectos: I) la relación entre el 
influencer y la marca que promociona, así como la forma de tributar las ganancias obtenidas por el pago de sus servicios; II) si la actividad de la marca promocionada es objeto de regulación especial; y III) un análisis del derecho comparado ${ }^{4}$.

La existencia de un contrato que regule los derechos y obligaciones entre las partes, es un buen punto de partida para resolver la entidad jurídica de la relación entre la marca y el influencer No obstante, existen cuestiones que escapan a la autonomía de la voluntad, por tratarse de normas de orden público que no pueden ser dejadas a la voluntad de las partes, como son los Derechos Fundamentales, el Derecho Tributario, las marcas y la propiedad intelectual e industrial, la competencia desleal, y otras materias reguladas de manera específica en los distintos países.

Tal como ocurre muchas veces con los embajadores de marca o los modelos, en el caso de los influencers, las marcas podrán optar entre la elaboración de un contrato de trabajo -incorporando al bloguero o influencer como trabajador de la empresa-, o la firma de un contrato mercantil, sin relación laboral, mediante en el cual se regulan la forma y periodicidad de las publicaciones en las redes sociales en las que se harán dichas menciones y los objetivos en audiencia o número de "likes" en cada caso.

Como señalan Linares Polaino y Velasco Lozano (2018, p. 381),

(...) la elección entre uno y otro dependerá, una vez más, de si, además de concurrir las notas de ajeneidad y dependencia, (i) se realiza una actividad artística y de si (ii) esta se ejecuta directamente ante el público o se graba para difundirla ante este.

De encontrarnos bajo las hipótesis planteadas por los autores, se regirá la relación laboral por el Real Decreto 1435/1985 de 1 de agosto, mientras que faltando cualquiera de los dos elementos copulativos señalados, nos encontraremos ante una relación laboral ordinaria regida por el Estatuto de los Trabajadores.

Para los citados autores, puede ser la solución más clara y "limpia" jurídicamente para la empresa, por cuanto los influencers graban videos, suben el material a las redes, promocionan sus productos, lo cual es un trabajo por cuenta ajena, con dependencia funcional y orgánica de la empresa (recibe instrucciones de los encargados de marketing de la compañía, no siendo autónomo en subir el contenido que le parezca). Si bien dicha solución es jurídica y comercialmente más conveniente para la marca (ya que controla el contenido del material subido a la red por el influencer) en la práctica es más utilizado el contrato mercantil, por cuanto otorga mayor grado de libertad a los influencers, que pueden promocionar más de una marca, sin convenios de exclusividad, generando un verdadero mercado, muchas veces administrados por agencias de publicidad, que contratan sus servicios a cambio de una comisión de los ingresos que éstos reciben de la marca.

Sobre este punto -analizando primero la normativa española-, podemos señalar que, independientemente del producto que promuevan, son aplicables a la actividad de estos prestadores de servicios en redes sociales el Estatuto de los Trabajadores, el Código de Comercio, el Código Civil, la Ley 34/2002 de Servicios de la Sociedad de la Información y Comercio Electrónico (en adelante LSSI), la Ley 3/2014 que modifica el texto refundido de la Ley General para la defensa de consumidores y usuarios (en adelante LGDCU), la 
Ley 34/1988 General de Publicidad (en adelante LGP), la Ley 3 de 1991 sobre competencia desleal (en adelante LCD), la Ley 29/2009 que modifica el régimen legal de la competencia desleal y de la publicidad para la mejora de la protección de los consumidores y usuarios (modificando aspectos esenciales tanto de la LCD como de la LGP), la Ley Orgánica Constitucional 1/1982 sobre protección del Honor, Intimidad y Propia Imagen, y finalmente el Reglamento General de protección de datos europeo de 2016 con entrada en vigencia en mayo de 2018 (en adelante RGPD).

En relación al Derecho chileno, reiteramos la regulación propia del Derecho común para este tipo de negocios, principalmente el Código Civil, el Código de Comercio, además de los artículos pertinentes de la Constitución Política de la República, garantías que pueden ser exigibles en sede jurisdiccional a través de la acción constitucional de protección del artículo 20 de la carta magna chilena. En relación a leyes especiales, mencionaremos la Ley 19.496 sobre Protección de los Derechos de los Consumidores, la Ley 17.336 de Propiedad Intelectual, la Ley 19.039 que establece normas aplicables a los privilegios industriales y protección de los derechos de propiedad industrial, la Ley 19.628 sobre Protección de la vida privada, actualmente en proceso de reforma para adaptar la regulación legal al RPGD europeo y a la reciente reforma constitucional del artículo 19 número 4, que incorporó mediante la Ley 21.096 a la Protección de datos personales y el tratamiento de éstos como garantía constitucional.

\section{c. Influencers: Competencia desleal y protección de los consumidores (Diez Bajo, 2020; Lema Devesa, 2018)}

El destinatario del mensaje de un influencer es el público. Al que se "invita" a consumir un determinado producto o servicio. Frente al legislador, ese público es un "consumidor" para efectos legales. Lo anterior no es baladí, por la especial preocupación que las distintas legislaciones han otorgado a los consumidores, como grupo intermedio especial, dotándolos incluso de acciones de clase frente a vulneraciones masivas de sus derechos.

$\mathrm{Al}$ respecto, cabe tener presente la protección del artículo 20 de la Ley 34/2002 (LSSI), claramente en protección y defensa del consumidor, el cual debe tener acceso a una información clara, oportuna y veraz, no solamente respecto de las características del bien o servicio que está adquiriendo, sino que igual respecto del canal publicitario y de la veracidad de los anuncios respecto de las propiedades del mismo.

Por su parte, la Ley chilena de Protección de los Consumidores (LPC) 19.496, define y establece los supuestos de publicidad en su artículo 1 número $4^{5}$, lo cual sin embargo, hace discutible que las condiciones y principios contenidos dicha norma puedan ser aplicables a cualquier tipo de relación, tal y como señala Martabit Sagredo (2019, p. 112).

Si nos apegamos al sentido estricto de la ley, los influencers no podrían considerarse directamente como prestadores del servicio y distribuidores del bien. Lo anterior, por cuanto la relación proveedor/consumidor -por lo menos para la ley chilena-, supone la existencia de un acto de comercio entre las partes y que el proveedor tenga la calidad de empresa formalmente establecida. 
Dicha solución si bien no deja en la indefensión al consumidor, libera de responsabilidad al influencer que promociona o publicita un producto que muchas veces a sabiendas, carece de las características propias que requiere el consumidor. Como señala Martabit Sagredo, (es) “(...) el artículo 33 de la LPC, el cual establece que toda la información contenida en la publicidad no debe contener expresiones que induzcan al consumidor a error o engaño (...)".

Con relación a los influencers, la LGP española igualmente prevé que sean honestos en relación al producto que promocionan, por cuanto no genera el mismo efecto en el público, que se "recomienden" las bondades de un determinado producto de motus propio por parte de una persona conocida en redes sociales, a que esa misma persona "recomiende" dicho producto a cambio de dinero o beneficios avaluables en dinero. Lo anterior lo recoge el artículo 9 de la LGP al señalar perentoriamente que "los anunciantes deberán asimismo desvelar inequívocamente el carácter publicitario de sus anuncios"'.

¿Qué sucede entonces cuando un influencer omite que está promocionando un bien o servicio a cambio de dinero? o ¿Existe sanción civil o penal para el que "recomienda" algo que no ha testeado por sí mismo? Consideramos que cada caso debe analizarse de manera puntual, ponderando hechos y Derecho, evitando así las denominadas "prácticas comerciales encubiertas", que recoge y sanciona el artículo 26 de la $\mathrm{LCD}^{7}$.

Al respecto, comparto la opinión de Díez (2018), en el sentido que la conducta subrepticia de un influencer al omitir la calidad publicitaria de un anuncio, podría ser tendencioso respecto del público, por cuanto dicha mención o recomendación obedece a un pago realizado por una empresa determinada. En esos elementos se centra el citado autor para resumir cuando nos encontraríamos frente a prácticas comerciales encubiertas: I) que se realicen por un medio de comunicación social; II) que la información entregada no sea otra cosa que publicidad, y finalmente, III) que una empresa haya otorgado un pago o retribución económica a la persona que está usando sus redes sociales como canal de promoción. Todo lo anterior, sin mención expresa a que se trata de una promoción pagada ${ }^{8}$. No debemos de perder de vista que en la mayoría de los casos, los influencers usan sus redes para promocionar moda, por lo tanto, deben ser cuidadosos, principalmente por las expectativas en relación al tallaje, condiciones culturales propias de los destinatarios del mensaje y a la universalidad del mismo. Como señala Barrientos Camus (2019, p. 141),

Los consumidores de moda afectados por estos mensajes se verán seducidos por declaraciones que desviarán su atención, generándoles expectativas diversas, sin conocer los verdaderos términos y condiciones de la contratación y los elementos esenciales de los productos o servicios que compran.

La importancia de una regulación estricta y protectora, tanto de la competencia desleal como de los derechos de los consumidores, se relaciona con la protección que el sistema jurídico ofrece a las marcas. No debemos olvidar que los influencers promocionan marcas que están protegidas en su gran mayoría, lo que significa igualmente una protección a los consumidores y al mercado. De ahí que el mal uso que haga un influencer ya sea de la marca, de sus atributos o promocionando productos que "parezcan" de una marca sin serlo, 
afectan no solamente a los consumidores, sino que también al ecosistema del mercado y de la competencia en general.

Como señala Carbajo Cascón (2015) a propósito de los sistemas de distribución selectiva, pero también aplicable a las promociones de los influencers en redes sociales, es importante evitar actos de comercio paralelo que afecten a la libre competencia como a los consumidores

(...) pues la reventa de productos de prestigio comercializados por terceros no integrados en la red y que no trasladan en sus establecimientos y actividad la sensación de lujo o prestigio esperada por el público, pueden acabar por destruir la imagen de la marca y sus productos, haciendo que pierdan atractivo entre el público.

Si un influencer promociona artículos sin consentimiento de la marca, o artículos que con o sin su conocimiento-, vulneran derechos exclusivos de una marca original, atenta con su conducta a las normas no sólo del Derecho marcario sino que a las normas de la libre competencia.

En Europa ${ }^{9}$, podemos mencionar que el Reino Unido, a través del Advertising Standards Authority (ASA) advirtió que más de 300 influencers estarían vulnerando normas relativas a publicaciones patrocinadas, sin hacer mención de ello. Por su parte, la Competition and Markets Authority (CMA) firmó un acuerdo con los mayores influencers del país para acordar un Código de buenas prácticas de la industria que transparente cuándo una publicación obedece a un acuerdo comercial previo con una marca.

No obstante se ha tratado de autorregular la transparencia con la cual los influencers promocionan productos de terceros a cambio de una remuneración -como el caso británico-, en la mayoría de los países, el Derecho ha conocido de estos conflictos cuando los casos se plantean directamente en los tribunales. En Alemania por ejemplo, encontramos sentencias que van en sentidos diferentes, ya sea obligando a los influencers a señalar que los datos o hashtags corresponden a publicidad -pagada o no-, o en otro sentido, tribunales que han eximido de etiquetar la publicidad no patrocinada como tal ${ }^{10}$.

En relación al Derecho estadounidense, regulatoriamente han ido más adelante que el Derecho europeo, principalmente a través de las directrices de la Federal Trade Comission (en adelante FTC), que ha normado expresamente la manera de relacionarse de los influencers con el público, evitando así afectaciones a la Libre Competencia o a los derechos de los consumidores.

La regulación y la exigencia de normas claras, que protejan los derechos de los consumidores y la Libre Competencia, comenzó en el año 2009. En el año 2015 se publicó un texto refundido sobre actuaciones de los blogueros en redes sociales, denominado ".com Disclosures How to Make Effective Disclosures in Digital Advertising”. Entre las principales directrices de dicho documento, se estableció la necesaria veracidad de los avisos realizados por inlfuencers, blogueros y youtubers (siendo ilegal cualquier promoción de contenido falso), además de respetar los principios de completitud en la información y de rigurosidad en relación con Instagram. Puntualmente, para efectos de especificar en todos los hashtags la directa mención al carácter publicitario de dicho contenido. 
El organismo regulador ha sido claro en considerar que existe publicidad en toda mención que se haga a un bien o servicio por parte de influencers, cuando la empresa no sólo otorga una compensación económica, sino que también cuando es la marca la que impone las condiciones para la promoción del producto ${ }^{11}$.

Para finalizar, conviene igualmente señalar la regulación proveniente del soft law, principalmente la relativa a la autorregulación de la propia industria de la publicidad, de carácter no jurídico y sin fuerza vinculante. En el caso español, el debate se ha centrado en el contenido que comparten en sus redes sociales los influencers y si ese contenido puede clasificarse como de carácter publicitario o no. Lo anterior no es menor, por cuanto podría considerarse una actividad publicitaria encubierta, situación prevista por la Guía Legal para Branded Content y Figuras Publicitarias afines de IAB Spain ${ }^{12}$.

En el caso chileno, podemos mencionar al Consejo Nacional de Autorregulación y Ética Publicitaria -en adelante CONAR-, establecido como órgano de jurisdicción voluntaria en el Código Chileno de Ética Publicitaria (CChEP), creado por la Asociación Nacional de Avisadores y la Asociación Chilena de Agencias de Publicidad para autorregular la actividad y los mensajes publicitarios en Chile, con el objeto que éstos se encuadren dentro de los principios de legalidad, honestidad, moralidad y veracidad.

Dentro de las ventajas de una regulación "extra jurídica", encontramos la mayor rapidez y adaptabilidad del CChEP a las variables de la industria de la publicidad, mucho mayor a la respuesta que pueda dar el ordenamiento jurídico, preso de los tiempos propios del proceso legislativo. Siguiendo a Martabit Sagredo, podemos señalar que "particularmente interesante resulta que el Código se encarga de establecer definiciones importantes y de gran precisión para la industria publicitaria, y en nuestra opinión, con mayor exactitud que los estándares legales de nuestro país (...)” (2019).

\section{Conclusiones}

Como se ha tratado de demostrar en el presente trabajo, la sociedad de la información en general, y las redes sociales en particular, han transformado no solamente la manera en cómo nos comunicamos, sino que igualmente nuestra forma de trabajar, de informarnos e incluso de comprar.

Sobre el mercado, podemos además señalar que en tiempos como los que estamos viviendo, el comercio digital no presencial ha adquirido una enorme importancia, no sólo por la situación puntual sanitaria a nivel mundial, sino que como omnicanalidad de ventas para las marcas de moda más importantes del mundo. En esa lógica, podemos señalar que las redes sociales se han transformado en el nuevo medio publicitario predilecto por la industria de la moda, y los influencers, los nuevos "vendedores digitales" de tendencias y consumo en general.

Asimismo, podemos señalar que al Derecho, estos nuevos "nativos digitales y publicitarios" lo han tomado por sorpresa para efectos de regular una actividad que en la actualidad se encuentra bajo la lupa del Derecho marcario, impositivo, de la competencia desleal, del consumo y a nivel de Derechos Fundamentales. Lo anterior, tanto por los ordenamientos 
nacionales como por el Derecho comunitario, en el caso de Europa. Y lo que es igualmente significativo, no sólo por el hard law, sino que también de una manera muy importante, por la autorregulación preveniente del soft law.

En suma, observamos que existe conciencia por parte de los diversos ordenamientos jurídicos, de esta nueva realidad, la cual ya está siendo objeto de regulación dirigida directamente a sus protagonistas. Hasta el momento -como en otras áreas de la economía-, vemos que la autorregulación de la industria ha sido más rápida, eficiente y oportuna para hacer frente a los conflictos que se derivan de esta actividad.

No obstante, se plantea para el Derecho de los Estados, un campo abonado de creatividad y cuidado en la prevención de conflictos de derechos que surgen día a día en un área vertiginosa en avances tecnológicos y cambios en la conducta de los consumidores.

\section{Notas}

1. Susy Bello Knoll (2019) explica que "Los primeros años del siglo XXI fueron testigos de un movimiento académico en distintas universidades de los Estados Unidos de América centrado en el estudio de las cuestiones jurídicas referidas al Sector de la Moda. América Latina no fue ajena a esta iniciativa y poco a poco comenzó a consolidar su lugar como referente internacional en el análisis de las diversas problemáticas que involucran a la industria de la Moda y sus actores, en relación con los temas legales. Los profesionales del derecho de la región han incursionado en el análisis de esta problemática desde varias ramas de las ciencias jurídicas que resultan útiles, como se verá, al desarrollo y dinámica empresarial del sector". Susy Bello Knoll: "Historia del Derecho de la Moda en América Latina”, en Derecho de la Moda, Jimena Rodríguez Donoso y Christian Vidal Beros, Coordinadores. Tirant Lo Blanch y Universidad Mayor, Madrid, 2019, página 11.

2. En relación al surgimiento e importancia práctica para el mundo digital y de la moda en particular, podemos revisar igualmente a María Lorente, "Influencers", en Revista Personal computer \& internet, ISSN 2530-1039, №. 155, 2015, págs. 22-27; Daniel Belanche Y Otros, "Followers' reactions to influencers' Instagram posts", en Spanish journal of marketing-ESIC, SSN 2444-9695, ISSN-e 2444-9709, Vol. 24, No. 1, 2020, págs. 37-53; Araceli Castello-Martínez y Cristina Del Pino Romero, "La comunicación publicitaria con influencers", en Redmarka: revista académica de marketing aplicado, ISSN-e 1852-2300, n. 14, 2015, págs. 21-50; SEBASTIÁN ANDRÉS CAPUCCI, "Los influencers y su impacto en la comunidad comercial", en Revista de doctrina, jurisprudencia, legislación y práctica, ISSN 0327-4012, No. 293, 2018, págs. 787-799.

3. Además de los autores citados expresamente, podemos mencionar igual que se hemos revisado a Verónica Pedrón, "La regulación de la publicidad de Influencers en España, Europa y más allá", publicado el 7 de febrero de 2019 en el Blog https://terminosycon diciones.es/2019/02/07/la-regulacion-de-la-publicidad-de-influencers-en-espana-europa -y-mas-alla/. Por su parte, es recomendable también el artículo de Ana Sánchez, "La publicidad de los influencers, un vacío legal que busca su fin", en https://blog.cuatrecasas.com/ propiedad-intelectual/la-publicidad-de-influencers-un-vacio-legal-que-busca-su-fin/ 
4. En este punto Fernando Díez considera como tercer punto de análisis "un vistazo a la normativa norteamericana de la FTC", lo cual en lo personal, puede ser algo restrictivo, tomando en cuenta la influencia del derecho continental en los sistemas jurídicos español e iberoamericano, más que las normas propias del Common Law. Es por ello que preferí tomar como tercer punto "un análisis del derecho comparado".

5. Artículo 1 número 4: "La comunicación que el proveedor dirige al público por cualquier medio idóneo al efecto, para informarlo y motivarlo a adquirir o contratar un bien o servicio, entendiéndose incorporadas al contrato las condiciones objetivas contenidas en la publicidad hasta el momento de celebrar el contrato", condiciones objetivas que a su vez consagra el artículo 28 de la misma ley: "a) Los componentes del producto y el porcentaje en que concurren; b) La idoneidad del bien o servicio para los fines que se pretende satisfacer y que haya sido atribuida en forma explícita por el anunciante; c) Las características relevantes del bien o servicio destacadas por el anunciante o que deban ser proporcionadas de acuerdo a las normas de información comercial; d) El precio del bien o la tarifa del servicio, su forma de pago y el costo del crédito en su caso, en conformidad a las normas vigentes; e) Las condiciones en que opera la garantía, y f) Su condición de no producir daño al medio ambiente, a la calidad de vida y de ser reciclable o reutilizable".

6. Artículo 9 de la LGP.

7. Artículo 26 de la LCD: "Se considera desleal por engañoso incluir como información en los medios de comunicación, comunicaciones para promocionar un bien o servicio, pagando el empresario o profesional por dicha promoción, sin que quede claramente especificado en el contenido o mediante imágenes y sonidos claramente identificables para el consumidor o usuario que se trata de un contenido publicitario".

8. Díez (2018) señala que "En lo relativo a las RRSS estaríamos ante el supuesto de que una influencer no incluya en un Tweet o en una foto de Instagram el Hashtag que haga referencia a que nos encontramos ante un contenido publicitario, como por ejemplo el hashtag \#publi o \#publicidad o algo similar".

9. A nivel europeo, podemos mencionar la Guía europea de buenas prácticas para el marketing de influencia, publicada por la Agencia Europea para la Ética Publicitaria (EASA de acuerdo a sus siglas en inglés) a fines del año 2018.

10. En relación al resto de países de la UE, señala Verónica Pedrón que “(...) si echamos un vistazo a la regulación de países como Bélgica, Holanda, Francia o Italia (entre otros), veremos que solo Italia (mediante un código de auto-regulación) y Holanda, mencionan el marketing de influencia de forma expresa. El resto lo engloban bajo prácticas engañosas o encubiertas en cuanto a publicidad, al no poder distinguir claramente el seguidor entre contenido editorial y comercial".

11. Como señala Díez (2018), respecto al caso donde “(...) la FTC alega que durante el mismo fin de semana de 2015, Lord \& Taylor les entregó un vestido modelo Paisley Asymmetrical Dress gratis a las 50 influencers y le pagó entre $\$ 1,000$ y $\$ 4,000$ a cada una por publicar una foto en Instagram y otras RRSS luciendo dicho vestido. Aunque podían personalizar el look, en el contrato la marca les obligaba a etiquetar a la marca en sus publicaciones y a poner el hashtag "\#DesignLab". Además, la marca les exigió una aprobación previa de las publicaciones. (...). Se trata de un caso de publicidad encubierta con 
influencers, pues en tales publicaciones se omitió el carácter publicitario de las mismas así como que se trataba de un contenido patrocinado".

12. En su sitio web, IAB Spain se define como “(...) la mayor asociación mundial de comunicación, publicidad y marketing digital. Presente en 47 países, en España arrancó su actividad en el año 2001 y desde entonces trabaja para trasladar el mensaje de la industria digital a todo el mercado".

\section{Referencias Bibliográficas}

Bajo, A. (2020). Curso Propiedad Intelectual y Derecho de la Competencia en Internet. Competencia y publicidad en el mercado virtual. Máster de Abogacía digital y nuevas tecnologías. Universidad de Salamanca.

Barrientos Camus, F. (2019). Relaciones entre el Derecho de consumo y el Derecho a la moda en Chile: Consumidores, proveedores y publicidad. En Rodríguez Donoso, J. y Vidal Beros, C. (Coord.). Derecho de la Moda. Madrid, España: Editorial Tirant Lo Blanch.

Belanche, D. y otros (2020). Followers' reactions to influencers' Instagram posts. Spanish journal of marketing. Volumen 24. (1), 37-53.

Bello Knoll, S. (2019). Historia del Derecho de la Moda en América Latina. En Rodríguez Donoso, J. y Vidal Beros, C. (Coord.). Derecho de la Moda. Madrid, España: Editorial Tirant Lo Blanch.

Capucci, S. (2018). Los influencers y su impacto en la comunidad comercial, en Revista de doctrina, jurisprudencia, legislación y práctica, ISSN 0327-4012, №. 293, págs. 787-799.

Carbajo Cascón, F. (2015). Distribución selectiva y moda. En Bello Knoll, S. y Echeverría, P. (Coord.) Derecho y Moda. Buenos Aires: Editorial Marcial Pons.

Carbajo Cascón, F. (2020). La protección de los diseños de moda en la Unión Europea (entre el diseño industrial y el diseño de autor). En Bello Knoll, S. (Coord.) Cuadernos del Centro de Estudios en Diseño y Comunicación $N^{\circ} 106$. Buenos Aires: Facultad de Diseño y Comunicación de la Universidad de Palermo.

Carbajo Cascón, F. (2019). Curso Derechos de autor y derechos afines en la sociedad de la información del Máster en Abogacía digital y nuevas tecnologías. Universidad de Salamanca.

Carbajo Cascón, F. (2019). Curso Propiedad Intelectual y derecho de la competencia en internet del Máster en Abogacía digital y nuevas tecnologías. Universidad de Salamanca.

Castello-Martínez, A. y Del Pino Romero, C. (2015) La comunicación publicitaria con influencers". Recuperado de: Redmarka: revista académica de marketing aplicado.

Díaz Corral, M. y Del Moral Fernández, U. (2018). Fiscalidad en el mundo de la moda. En Ortega Burgos, E (dir.). Fashion Law (Derecho de la Moda). Madrid: Editorial Thompson Reuters Aranzadi.

Díez, F. (15 de mayo de 2018). El régimen jurídico de los Influencers. Recuperado de https:// www.linkedin.com/pulse/aspectos-legales-tener-en-cuenta-las-colaboraciones-con-fer nando-d\%C3\%ADez/

Diccionario Panhispánico de Español Jurídico (S.F.) Recuperado de: https://dpej.rae.es/ lema/influencia 
Eikel, C. (3 de agosto de 2018). New decision on German influencer marketing: Courts in Berlin require disclosure as advertisement even for non-sponsored posts. Recuperado de https://www.lexology.com/library/detail.aspx?g=12d4d756-d753-4d0e-be47-4fd$70 \mathrm{c} 62 \mathrm{acad}$

Eikel, C. (10 de julio de 2018). German influencer fight back against the German competition watchdog on the rules of influencer advertising. Recuperado de https://mediawrites.law/ german-influencer-fights-back-against-the-german-competition-watchdog-on-the-rules -of-influencer-advertising/

Ennochi, J. (2002). Le contrat d'image. L'IMAGE MENACÉE?, Actes du Forum Légipresse du 4 octobre 2001. Francia: Collection Légipresse.

Fernández-Lasquetty, J. y otros (2918). Derecho de Imagen. En Ortega Burgos, E (dir.). Fashion Law (Derecho de la Moda). Madrid: Editorial Thompson Reuters Aranzadi.

García Vásquez, D. (18 de julio de 2019). Todo lo que deben saber sobre la tributación de los influencers. Recuperado de: https://www.dgvfiscal.es/todo-lo-que-deben-saber-sobrela-tributacion-de-los-influencers/

Lema Devesa, C. (2018). Tendencias actuales del derecho de la publicidad: la problemática autorregulación publicitaria en España. Revista de Ciencias Sociales. Volumen 6 (1). Universidad Complutense de Madrid. Recuperado de: https://doi.org/10.17502/m.rcs. v6i1.225

Linares Polaino, J. A. y Velasco Lozano, J. (2018). Contratación laboral y mercantil en el sector de la moda y el lujo. En Ortega Burgos, E (dir.). Fashion Law (Derecho de la Moda). Madrid: Editorial Thompson Reuters Aranzadi.

López Albán, G. (Agosto 2019). Tributación de Influencers. En Chipana Catalán, J.(Coord.). DERECHO Y NUEVAS TECNOLOGÍAS: EL IMPACTO DE UNA NUEVA ERA. Bogotá, Colombia: Editorial jurídica Themis. Recuperado de: https://www.researchgate.net/ publication/335442285_Tributacion_de_influencers

Pedrón, V. (7 de febrero de 2019) La regulación de la publicidad de Influencers en España, Europa y más allá. Recuperado de https://terminosycondiciones.es/2019/02/07/la-regu lacion-de-la-publicidad-de-influencers-en-espana-europa-y-mas-alla/

Martabit Sagredo, M. J. (2019). Publicidad engañosa y su impacto en la industria de la moda. En Rodríguez Donoso, J. y Vidal Beros, C. (Coord.). Derecho de la Moda. Madrid, España: Editorial Tirant Lo Blanch.

Montoya, A. (5 de febrero de 2020). De Influencers a empresarias: Las claves de Ferragni, Pombo y Bimani. Recuperado de: https://enriqueortegaburgos.com/de-influencers-a-em presarias-las-claves-de-ferragni-pombo-y-bimani/

Montoya, A. (18 de noviembre de 2019). Kel Calderón, su crisis dentro de la crisis. Recuperado de: http://www.lwyr.cl/opinion/kel-calderon-su-crisis-dentro-de-la-crisis/

Montoya, A. (9 de marzo de 2020). La responsabilidad social de los Influencers. Recuperado de: https://enriqueortegaburgos.com/responsabilidad-social-influencers/

Montoya, A. (5 de diciembre de 2019). Moda e Influencers: ¿Puede la industria vivir sin María Pombo o Chiara Ferragni? Recuperado de : https://enriqueortegaburgos.com/ la-industria-de-la-moda-puede-vivir-sin-maria-pombo-y-otros-influencers/.

Moreno, M. (15 de enero de 2019) Los 'influencers' que no dejan claro sus acuerdos con las marcas, investigados en Reino Unido. Recuperado de https://www.trecebits. 
com/2019/01/15/los-influencers-que-no-dejan-claro-sus-acuerdos-con-las-marcasinvestigados-en-reino-unido/

Nerson, R. (1971). La protection de la vie privée en droit positif francais. Revue international du droit comparé. Volumen 32. Paris. p.760, citado por Acquarone, D. (1085) L'ambigüité du droit à l'image. Recueil Dalloz Sirey. Volumen 24. Paris.

Rudi, C. (2019). Los Derechos de Propiedad Intelectual en tiempos de Instagram. En Rodríguez Donoso, J. y Vidal Beros, C. (Coord.). Derecho de la Moda. Madrid, España: Editorial Tirant Lo Blanch.

Rodríguez Donoso, J. (2019). El conflicto entre regulación y competencia libre en la industria de la moda. En Rodríguez Donoso, J. y Vidal Beros, C. (Coord.). Derecho de la Moda. Madrid, España: Editorial Tirant Lo Blanch.

Sánchez, A. (28 de octubre de 2019). La publicidad de los influencers, un vacío legal que busca su fin. Recuperado de: https://blog.cuatrecasas.com/propiedad-intelectual/lapublicidad-de-influencers-un-vacio-legal-que-busca-su-fin/

Silván Rodríguez, F. y Muñoz Rodríguez, J. (2018). Estrategias comerciales: marketing y publicidad. En Ortega Burgos, E (dir.). Fashion Law (Derecho de la Moda). Madrid: Editorial Thompson Reuters Aranzadi.

Wakefield, J. (23 de enero de 2019). Social media stars agree to declare when they post ads. Recuperado de https://www.bbc.com/news/technology-46960179

\section{Normas}

Constitución Española. Boletín Oficial del Estado (27 de diciembre de 1978). Recuperado de: https://www.boe.es/legislacion/documentos/ConstitucionCASTELLANO.pdf.

Constitución Política de la República de Chile. Boletín Oficial (22 de septiembre de 2005). Recuperado de: https://www.leychile.cl/Navegar?idNorma=242302

Real Decreto español No1435/1985 (1 de agosto de 1985). Recuperado de: https://www.boe. es/buscar/act.php?id=BOE-A-1985-17303\#: :text=Real\%20Decreto\%201435\%2F1985\% 2C\%20de,los\%20artistas\%20en\%20espect\%C3\%A1culos\%20p\%C3\%BAblicos.

Ley española N³4/1988 (1 de agosto de 1988). Recuperado de https://www.boe.es/buscar/ pdf/1988/BOE-A-1988-26156-consolidado.pdf

Ley chilena $\mathrm{N}^{\circ} 19.496$ (7 de marzo de 1997). Recuperado de https://www.leychile.cl/Navegar ?idNorma $=61438$.

Federal Trade Comission (EE.UU.) (3 de diciembre de 2019). Disclosures 101 for social media influencers. Recuperado de https://www.ftc.gov/system/files/documents/plain-lan guage/1001a-influencer-guide-508_1.pdf

Página web de IAB, asociación española de la industria publicitaria. Recuperado de https:// iabspain.es/quienes-somos-iab-spain\#iab-spain-misin.

Página web del Consejo Nacional de Autorregulación Publicitaria de Chile (CONAR). Recuperado de https://www.conar.cl/sii-pone-su-foco-en-influencers-con-mas-de-100mil-seguidores/

Página web de European Advertising Standars Alliance EASA. Recuperado de https://www. easa-alliance.org/ 


\begin{abstract}
The birth of the influencers phenomenon within advertising linked to social networks and technology and its necessary regulation by the Law is analyzed. The importance of delimiting and defining when the promotion of a product through these influencers is paid or not is presented and the legal consequences for the free market and consumers thereof.
\end{abstract}

Keywords: Influencers - Law - Publicity - Unfair competition - Regulation.

Resumo: Analisa-se o nascimento do fenômeno dos influenciadores na publicidade vinculada às redes sociais e de tecnologia e sua necessária regulamentação pela Lei. A importância de delimitar e definir quando a promoção de um produto por meio desses influenciadores é paga ou não é apresentada e as consequências jurídicas para o mercado livre e seus consumidores.

Palavras chave: Influencers - Direito - Publicidade - Competicao injusta - Regulacao.

[Las traducciones de los abstracts fueron supervisadas por el autor de cada artículo] 